\title{
The recycled aggregate concrete filled steel tube finite element model Bing Wang ${ }^{a}$, Xiao Liu ${ }^{b *}$, Juntao Bao ${ }^{c}$
}

School of Architectural and Civil Engineering, Shenyang University, Shenyang, 110044, China

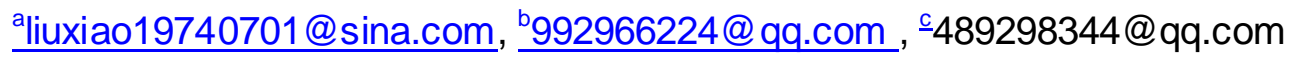

${ }^{* *}$ Corresponding author: Professor Xiao Liu, School of Architectural and Civil Engineering, Shenyang University, Shenyang, 110044, China

Tel: 8610 62721531, E-mail address: 992966224@qq.com

Keywords: finite element analysis, recycled aggregate concrete, model building, constitutive relationship, axial compression

Abstract. Based on choose the constitutive relationship of core recycled concrete and steel in a reasonable way. It used the ABAQUS to establish the finite element analysis mode of recycled aggregate concrete filled steel tube subjected to axial compressive. It introduced the method and process of establish the mode in detail, and compared the mode calculation results and the test results, it proved modeling method is right.

\section{Introduction}

The accumulation of waste concrete bring a great negative impact on ecological environment, and how to use the recycled concrete for ecology, environmental protection and the sustainable development of society have urgent practical significance. Recycled concrete is recycling used the waste concrete, its compressive strength and elastic modulus is smaller than the same mix proportion of normal concrete, that lead to its mechanical properties durability and deformation ability is poor. But compared with normal concrete, the recycled aggregate concrete has good characteristics, such as temperature lag, high temperature resistance well, these characteristics make it less loss in mechanical properties after exposed to high temperature [1-2].

Recycled aggregate concrete filled steel tube is a new composite, which pull the recycled aggregate concrete into steel tube, it fully give play to the concrete filled steel tubes' advantages, and it also reasonable to solve the waste concrete brings the huge pressure of the ecological environment. Researchers in china and abroad has conducted a series of research on recycled aggregate concrete filled steel tube, Yang[3-4] has studied the mechanical properties of recycled aggregate concrete filled steel tube, and the mechanical properties after exposed to high temperature under axial compressive. In this paper, on the basis of the experimental research, it used the constitutive relationship of core recycled concrete and steel, which forward by Hou[5]. It introduced the method and process of establish the mode in detail, it introduced the method and process of establish the mode in detail, in order to provide the basis to the research of recycled aggregate concrete filled steel tube.

\section{The process of ABAQUS model building}

Unit selection In this paper, when building model, the steel parts were built in the 3D model space, because when the scale of the structure in one direction or the scale of the thickness is far less than 
the other directions and negligible stress along the thickness direction, it can be modeled using shell elements. So the basic characteristics of the steel tube, so it used S4R shell elements, S4R is 4 node deformation finite linear reduced integral membrane strain shell element, its stable performance, and widely used. Shell in the form of deformable, stretching. In the description of the shell when the cross section defines the thickness of the shell is 0.003 meters. In order to improve the accuracy and precision of the calculation, the thickness of shell thickness direction integral click for 7 , thickness of integral rules to choose Simpson rule.

In this paper, when building model, the steel parts were built in the 3D model space, Because when the scale of the structure in one direction or the scale of the thickness is far less than the other directions and negligible stress along the thickness direction, it can be modeled using shell elements. So the basic characteristics of the steel tube, so it used S4R shell elements, S4R is 4 node deformation finite linear reduced integral membrane strain shell element, its stable performance, and widely used. Shell in the form of deformable, stretching. In the description of the shell when the cross section defines the thickness of the shell is 0.003 meters. In order to improve the accuracy and precision of the calculation, the thickness of shell thickness direction integral click for 7 , thickness of integral rules to choose Simpson rule.

When model building, recycled concrete and both ends of the cover plate use deformable, stretching of the three-dimensional entity unit. Because when simulated the recycled aggregate concrete filled steel tube under axial compressive, the local mesh will produce serious distortion, so used the mesh refinement of the linear C3D8R, reduced integral unit, it can reduce the degree of freedom and save computing time. In the finite element simulation, both ends of the plate is assumed as rigid body.

Custom properties Custom properties is presented in this paper, according to above to determine the constitutive relations of steel and recycled concrete definition, when definition the plastic behavior of core concrete used Concrete Damaged Plasticity in ABAQUS. The model of concrete damage can be divided into two cases: compression crushing and tensile crack, compression and tensile damage variable is used to describe the concrete damage caused by the stiffness degradation, it can be well simulated the plastic performance of concrete.

Analyze step In this paper, when simulate the recycled aggregate concrete filled steel tube in the process of loading, the steel tube, recycled aggregate concrete, recycled concrete and steel tube and will involve in areas such as the contact surface of the material nonlinearity and bo undary nonlinearity and geometric nonlinear problem, in the analysis of the nonlinear and linear problem in solving the equation of a single system is different, but the incremental step by step is applied for a given load and gradually obtained the final answer So in this paper, when solve the nonlinear problem, it used Newton-Raphson, by incremental iterative method for nonlinear solution of the problem.

Inte raction In this paper, when model building, it involved the contact between the two parts: the contact between steel tube and core concrete, the contact between both ends plate and core concrete, and the contact between the steel tube and core concrete.

Firstly defines the contact properties between the core concrete and steel tube, and the core concrete and the cover plate, between the steel tube and core concrete in the tangential friction coefficient behavior is taken to be 0.6 , there is no friction between the core concrete and the cover plate. When defined the contact between steel tube and core concrete, the slave surface is the outer surface of the core concrete, the master surface is the inner surface of steel tube, the sliding formulation between the master surface and the slave is small sliding. When defined the contact between core concrete and the cover plate, using the finite sliding, and defined the contact between plate and core concrete also used the finite sliding. When define the constraints, the contact between steel tube and plate type for shell -to-solid coupling, plate and its reference point is defined as a rigid body together.

Boundary condition and load Because of the model building is recycled aggregate concrete filled steel tube under axial compression, so the fixed end plate implementation does not occur in any 
direction of displacement and angle of rigid constraints, limited U1 $=\mathrm{U} 2=\mathrm{U} 3=\mathrm{UR} 1=\mathrm{UR} 2=$ $\mathrm{UR} 3=0$, the constraint of $\mathrm{X}$ and $\mathrm{Y}$ direction displacement and the rotation of the $\mathrm{X}, \mathrm{Y}, \mathrm{Z}$ direction, make the component can happen displacement in the $\mathrm{Z}$ direction, limited $\mathrm{U} 1=\mathrm{U} 2=\mathrm{UR} 1=\mathrm{UR} 2=$ $\mathrm{UR} 3=0$, not qualified U3 for axial ( $\mathrm{Z}$ direction); When loading, based on displacement control of load, namely at the load end displacement along the $\mathrm{Z}$ direction on 0.02 meters.

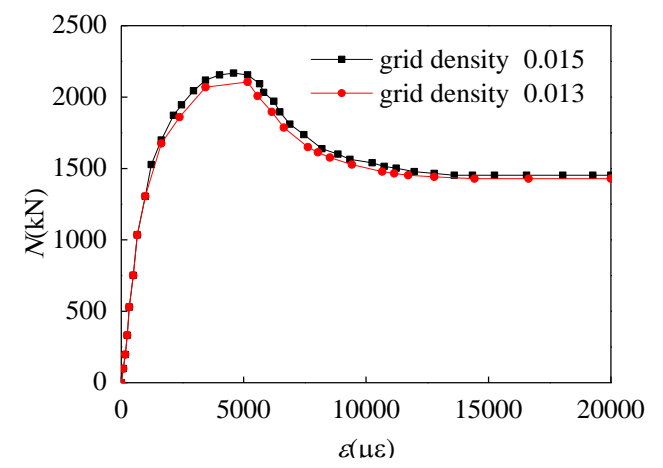

Fig. 1The contrast graph of different grids

Mesh Meshing is an important part in finite element model building, meshing need to large work load and consider more question, meshing will be directly affected on the computing speed and the accuracy of the results . the more the grid number, the more accuracy of the calculation results, but it makes the computing speed slow down, computing scale increases, the calculation accuracy is almost no longer improve, so in meshing, it should consider the two reasons.

This paper was divided into several different on the grid, and compared the calculation results, Fig. 1 shows the different results of the grid size were 0.013 and 0.015 , can be seen from the graph, the calculate results were little different when used two kinds of mesh division method, but the latter's calculate time was significantly faster than the former, so this paper used the grid size of 0.015 ,Fig. 2 show the schematic diagram of the grid division of each part.

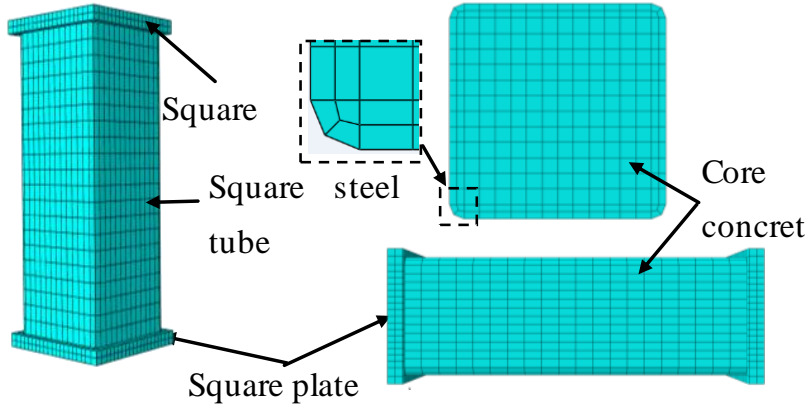

(a) Square

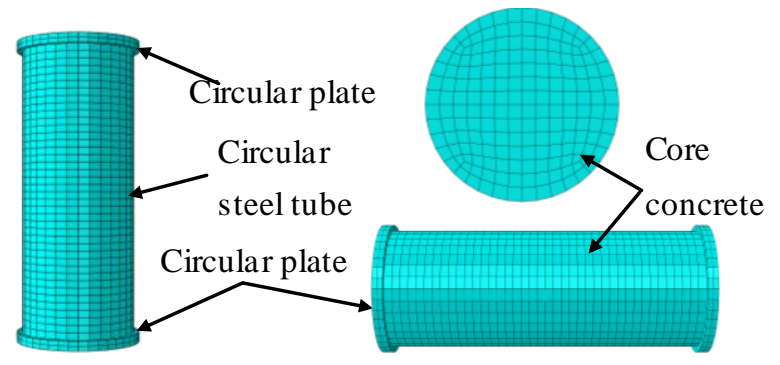

(b) Circular

Fig. 2 The schematic diagram of the grid division

\section{Finite element models of the validation}

To verify the correctness of the recycled concrete filled steel tube model in this article, based on the finite element software ABAQUS to establish finite element model of the same as the size and material parameters, compare calculation results with the experimental results of ABAQUS. The nominal stress - strain curves of calculate results and test results were shown in Fig.3, it can be seen, the two curves are basically the same and in good agreement, so finite element analysis results can reflect the stress of the recycled aggregate steel tube under axial compressive. 


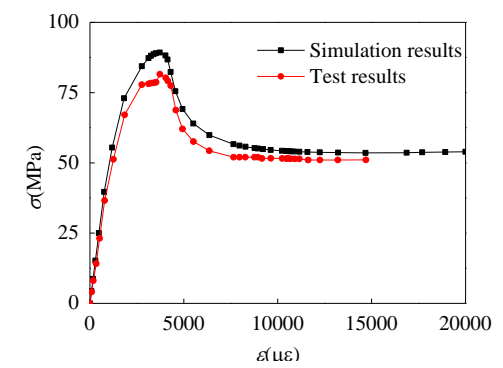

(a) R0

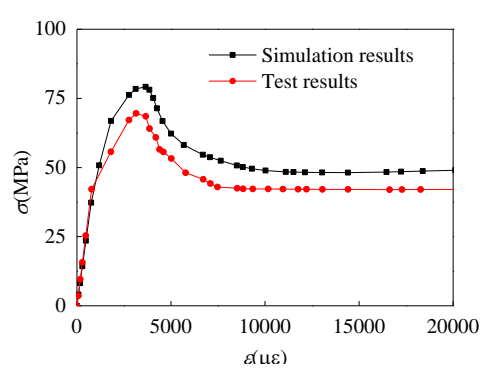

(d) R3

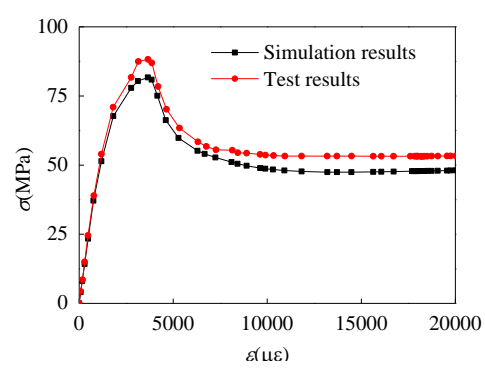

(b) R1

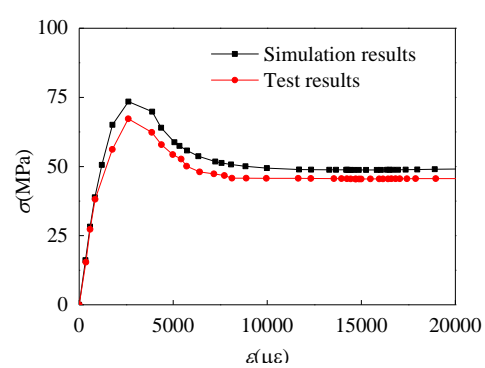

(e) R4

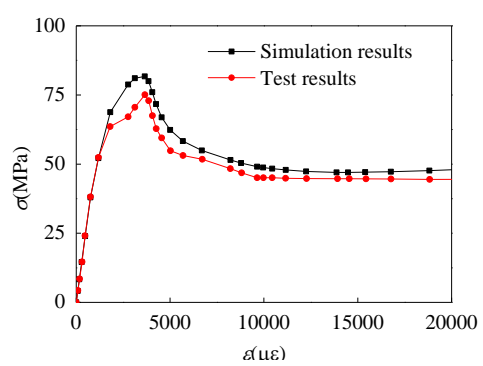

(c) R2

Fig3. The stress-strain curves

\section{Conclusion}

It can be seen that the used of unit, the contact between each part, the meshing, the boundary conditions and the loading method is reasonable, the finite element analysis results are in good agreement with test results, so can be think the finite element model is correct.

\section{Acknowledge ment}

It is a project supported by National Science Foundation (51308347).

It is a project supported by Shenyang Science Plan project (F13-171-9-00).

It is a project supported by Shenyang Science Plan project (F14-028-2-00)

It is a project supported by Shenyang Science Plan project(F14-210-6-00)

It is a project supported by Liaoning science public research funds(2014004025)

\section{Reference:}

[1]Xiao Jianzhuang, Recycled concrete [M].Beijing: China Building Industry Press, 2008, 55-65.

[2] Liu Xiao, Zhao Lei. Significance of fire resistance performance on the recycled concrete-filled steel tube, Journal of Applied Mechanics and Materials, 2012(6):1423-1427.

[3]You-Fu Yang, Lin-Hai Han. Experimental behaviour of recycled aggregate concrete filled steel tubular columns.[J]. Journal of Constructional Steel Research.2006,62:1310-1324.

[4]Y.F.Yang,R.Hou.Experimental behaviour of RACFST stub columns after exposed to high temperatures.[J].Thin-WalledStructures .2012,59:1-10.

[5]Hou Rui.Study on compressive behavior of recycled aggregate concrete filled steel tubes after exposed to high temperature.[D]Dalian:Dalian university of technology,2011. 